\title{
Effect of changing journal clubs from traditional method to evidence-based method on psychiatry residents
}

Farhad Faridhosseini ${ }^{\prime}$

Ali Saghebi ${ }^{2}$

Majid Khadem-Rezaiyan ${ }^{3}$

Fatemeh Moharari

Maliheh

Dadgarmoghaddam ${ }^{3}$

'Psychiatry and Behavioral Sciences Research Center, ${ }^{2}$ Department of Psychiatry, Psychiatry and Behavioral Sciences Research Center, ${ }^{3}$ Community Medicine, Faculty of Medicine, Mahhad University of Medical Sciences, Mashhad, Iran
Correspondence: Maliheh

Dadgarmoghaddam

Community Medicine, Faculty of

Medicine, Mahhad University of Medical

Sciences, Azadi Square, Pardis Campus,

Mashhad 91779-48944, Iran

Tel +985138828888

Fax +985I 38828560

Email dadgarmm@mums.ac.ir
This article was published in the following Dove Press journal:

Advances in Medical Education and Practice

10 August 2016

Number of times this article has been viewed

Introduction: Journal club is a valuable educational tool in the medical field. This method follows different goals. This study aims to investigate the effect on psychiatry residents of changing journal clubs from the traditional method to the evidence-based method.

Method: This study was conducted using a before-after design. First- and second-year residents of psychiatry were included in the study. First, the status quo was evaluated by standardized questionnaire regarding the effect of journal club. Then, ten sessions were held to familiarize the residents with the concept of journal club. After that, evidence-based journal club sessions were held. The questionnaire was given to the residents again after the final session. Data were analyzed through descriptive statistics (frequency and percentage frequency, mean and standard deviation), and analytic statistics (paired $t$-test) using SPSS 22.

Results: Of a total of 20 first- and second-year residents of psychiatry, the data of 18 residents were finally analyzed. Most of the subjects (17 [93.7\%]) were females. The mean overall score before and after the intervention was $1.83 \pm 0.45$ and $2.85 \pm 0.57$, respectively, which showed a significant increase $(P<0.001)$.

Conclusion: Moving toward evidence-based journal clubs seems like an appropriate measure to reach the goals set by this educational tool.

Keywords: journal club, evidence-based, residents, education method

\section{Introduction}

Journal club is defined as a regular gathering of a group of people to appraise the latest published articles. ${ }^{1}$ It is a flexible framework for teaching basic sciences and clinical skills. One of the earliest resources addressing journal club is the writings of Sir James Paget, a British surgeon and the founder of modern pathology in $1800 .{ }^{1}$ At the time, students and residents gathered together at the cafeteria of the hospital and had discussions about journals. ${ }^{1}$ However, the classic version of journal club was first employed by Sir William Osler in 1875 at McGill University in Montreal, Canada, and afterward at Johns Hopkins University to train medical assistants. ${ }^{1}$ Since then, it has been used as a framework to study and discuss the latest medical research. Therefore, journal club has been used as an educational method in medicine for more than 100 years. ${ }^{1}$ In the past, the aim of journal clubs was merely to update participants' knowledge and information. ${ }^{1}$ Today, however, it is used as a method to teach critical thinking and to encourage performing clinical procedures based on evidence-based medicine, research methodology, biostatistics, and epidemiology. ${ }^{2,3}$ In some cases, the aim of journal clubs is to have group discussions in English about patients, diseases, 
and specific clinical conditions based on which a study is selected. ${ }^{4,5}$ Today, journal clubs as an effective educational method have attracted more attention. ${ }^{46}$ Some of the goals of journal clubs include answering important clinical questions raised during patient management process, teaching students and residents how to appraise and analyze the results of studies, and developing Critically Appraised Topics to respond quickly to questions raised in rounds, morning reports, and developing protocols. ${ }^{6}$

In fact, evidence-based practice in a journal club happens when an individual makes a question about a clinical problem a priority instead of a specific topic for the title of his/her presented article. In this educational method, evidence-based medicine is followed in each journal club session. In other words, the best studies and scientific evidence for a clinical question are sought. Moreover, articles are appraised, and they are not blindly accepted even if they are published in the most prestigious journals.

Interestingly, studies show that only $5 \%$ of the articles of the world's top five prestigious journals enjoy an absolutely sound methodology, and only $0.5 \%$ of the findings are reliable and valid. Therefore, it is always recommended that articles and publications should be appraised and evaluated to reduce performance risk. ${ }^{6}$ On the other hand, the points mentioned in articles are not supposed to be entirely applied in physicians' actual work environment. Rather, they should be considered along with individual experience, specific conditions, and patients' needs and values so that they can be applicable. Hence, in the presence of experts, journal clubs can provide a suitable environment for solving health system problems. In other words, in an evidence-based journal club, one should try to find appropriate solutions and answers for actual clinical problems and questions instead of searching for one's favorite topic among the titles of articles. ${ }^{6}$

Given the importance of this issue, and since according to researchers, evidence-based journal clubs are not held in many clinical educational departments in our university, this study was designed and carried out in the Department of Psychiatry at Mashhad University of Medical Sciences for the first time to investigate the effect of evidence-based journal club as an educational method on the skills of the residents.

\section{Method}

\section{Ethics}

This study was approved by ethical boards of Mashhad University of Medical Sciences (930785).

\section{Research design and sampling}

This study was conducted using a before-after design. All the first- and second-year residents of psychiatry were included in the study. The traditional journal club was held for many years in this department, and all the residents and faculty members were unsatisfied with it. Before holding the sessions, some items were examined and modified step by step. These steps included following the approved curriculum of psychiatric residency training program, selecting a moderator, determining goals, preparedness of presenters, and planning the active participation of department faculties, especially senior ones in journal club as a supervisor. This article was approved by the ethical board of Mashhad University of Medical Sciences (code: 930785) and verbal informed consent was given from all the participants.

\section{Intervention}

First, the status quo was evaluated using a standardized questionnaire regarding the effect of journal club (it was designed and validated by Shokouhi et $\mathrm{al}^{7}$ ). Then, ten sessions were held to familiarize the residents with the concept of journal club, its history, goals, types of studies, evidence pyramid (the evidence-based medicine pyramid is simply a diagram that was created to help us understand how to weigh different levels of evidence), and how to search and critically appraise research articles. After that, evidence-based journal club sessions were held for all subjects. In these sessions, the residents searched databases for their clinical questions with the help of the journal club organizer (one leader in each session) and community medicine specialist. Then, the best article was selected according to the evidence pyramid for each session in consultation with the supervisors. Articles were selected in a way that all residents could become familiar with different types of studies, from the bottom to the top of the evidence pyramid. The article was emailed to all members of the target group (residents and faculty members) about a week earlier. Moreover, the group was instructed to send the article through social networks limited to group members.

All sessions started at 8:30 am and ended at $10 \mathrm{am}$. They were held at the residents' conference hall. A resident would present the article, and then scientific discussions about the article would take place, which were followed by questions from residents and the answers. Next, the methodology of the study was explained. Statistical analyses were elaborated with the help of a community medicine specialist, and residents' questions were answered. After the article was fully understood, the article was appraised based on the critical appraisal guidelines (a systematic process used to identify the strengths and weaknesses of a research article to assess 
the usefulness and validity of research findings). All articles and their appraisals were archived from the very beginning of the sessions so that they could be later used as a guide for residents. This training course (evidence-based journal club) was held over 18 months, and it was continued till now in this department. The sessions were held once every 2 weeks, and the journal clubs were taught and supervised by a community medicine specialist. The questionnaire was given to the residents again after the final session. Those who were absent for more than three consecutive sessions were excluded from the study.

This questionnaire consists of eight domains, including searching for articles in databases (four questions), understanding and appraisal of scientific articles (five questions), slide preparation (two questions), speech and presentation (seven questions), study habits (three questions), improving treatment methods (three questions), collaboration with the faculty members of other departments (two questions), and overall effect of journal club sessions (two questions). The questions were rated from poor ( 1 point) to excellent ( 5 points) based on a 5-point Likert scale. To calculate the score in each area, the mean score of the questions of that particular area was calculated, which ranged from 1 to 5 . Data were analyzed through descriptive statistics (frequency and percentage frequency for qualitative variables, and mean and standard deviation for quantitative variables) and analytic statistics (paired $t$-test) using SPSS 22 (IBM Corporation, Armonk, NY). $P<0.05$ was considered statistically significant.

\section{Results}

Of the total of 20 first- and second-year residents of psychiatry, the data of 18 residents (10 first-year residents and 8 second-year residents) were finally analyzed (two residents

Table I Scores before and after the educational course

\begin{tabular}{|c|c|c|c|}
\hline Domains & $\begin{array}{l}\text { Before } \\
\text { intervention }\end{array}$ & $\begin{array}{l}\text { After } \\
\text { intervention }\end{array}$ & $P$-value \\
\hline $\begin{array}{l}\text { Searching for articles in } \\
\text { databases }\end{array}$ & $1.8 I \pm 0.6$ & $2.68 \pm 0.83$ & 0.003 \\
\hline $\begin{array}{l}\text { Understanding and appraisal of } \\
\text { scientific articles }\end{array}$ & $1.52 \pm 0.42$ & $2.6 I \pm 0.8 I$ & $<0.001$ \\
\hline Slide preparation & $2.02 \pm 0.7 I$ & $3.05 \pm 0.93$ & 0.001 \\
\hline Speech and presentation & $2.05 \pm 0.69$ & $2.92 \pm 0.67$ & $<0.001$ \\
\hline Study habits & $2.03 \pm 0.76$ & $3.0 \pm 0.84$ & 0.002 \\
\hline Improving treatment methods & $1.85 \pm 0.52$ & $2.85 \pm 0.75$ & $<0.001$ \\
\hline $\begin{array}{l}\text { Collaboration with the faculty } \\
\text { members of other departments }\end{array}$ & $1.58 \pm 0.79$ & $3.05 \pm 0.92$ & $<0.001$ \\
\hline $\begin{array}{l}\text { Overall effect of journal club } \\
\text { sessions }\end{array}$ & $1.63 \pm 0.68$ & $2.91 \pm 0.80$ & $<0.001$ \\
\hline
\end{tabular}

Note: Data are shown by mean \pm standard deviation. were excluded from the study due to absence from more than three sessions). One of the subjects was male (6.3\%) and the rest (17 subjects) were females $(93.7 \%)$. The mean overall score before and after the intervention was $1.83 \pm 0.45$ and $2.85 \pm 0.57$, respectively, which showed a significant increase $(P<0.001) . \eta^{2}$ was calculated to evaluate the overall effectiveness, and it was 0.67 , which indicated good effectiveness of this intervention. Moreover, the scores in all areas increased after the training course (Table 1). The highest increase belonged to the following areas: "collaboration with the faculty members of other departments" (1.46) and "overall effect of journal club sessions" (1.27). The lowest increase belonged to "searching for articles in databases" (0.86).

Layered analysis based on resident's academic year showed that the overall score as well as the score of each area significantly improved among the second-year residents. However, although the overall score among the first-year residents improved, no significant change was observed in the areas of "searching for articles in databases" ( $P=0.129)$ and "study habits" $(P=0.065)$. Since there was only one male in the study, it was not possible to analyze the data by sex.

\section{Discussion}

The results of this study showed that the overall scores and the scores for each area improved after the intervention, which shows the good effectiveness of an evidence-based journal club. One of the goals of evidence-based journal clubs is to help critically appraise medical literature and make fundamental changes in clinical practice. ${ }^{8,9}$ Therefore, this study showed that this goal can be achieved by changing journal clubs from a traditional method to an evidence-based method.

It is believed that journal club sessions can improve study habits and provided updated information, ${ }^{10}$ as observed in this study after the intervention.

One of the major points in effective journal club sessions is the active participation of the faculty members and also members of other departments to review and appraise articles. Faculty members' involvement in the teaching process of journal club sessions leads to more extensive participation of residents within sessions. ${ }^{11-13}$ In this study, the highest improvement was observed in the area of collaboration with the faculty members of other departments. In the new method, a community medicine specialist attended all sessions to carry out a systematic review of the articles. In a study by Akhund et al, ${ }^{14}$ over $85 \%$ of respondents perceived a change in critical appraisal skills and over $65 \%$ indicated an increase in knowledge in the topic areas. In addition, resi- 
dents indicated that they value attending and preparing for journal club. They agreed that presentation of their research work helps them to refine it.

Although the total score of the first-year residents improved, no significant change was observed in the areas of "searching for articles in databases" and "study habits". This could be due to the first-year residents being less familiar with the technical terms and studying less compared to the second-year residents.

This study also had some limitations. One limitation was that individual changes were measured on a self-report basis, which may not be an accurate measure of skills improvement. This should be confirmed in future studies through more detailed objective assessments, if possible. However, various studies with randomized clinical trial and cohort designs have also confirmed improvement in areas, such as knowledge, skill, behavior, and critical thinking. ${ }^{15-20}$

Another limitation of this study was using a 5-point Likert scale and including neutral opinions, which can lead to central tendency bias. The reason for this choice was because of some sensitive questions in the questionnaire. Nevertheless, in this study, the answers often followed one of the two choices, which dispelled our concerns. The small sample size and that the study was done in a single location were other limitations of this study.

One of the strengths of this study that makes the results of this intervention valuable was the acceptable number of psychiatry residents participating in the study.

\section{Conclusion}

In today's world, good medicine requires good information and certain capabilities such as data interpretation, understanding information, and application of research results through learning critical appraisal. Accordingly, evidence-based journal clubs are a perfect educational tool in this area.

\section{Acknowledgments}

We hereby thank the Head of Department for her full support and emphasis on holding regular evidence-based journal clubs. We are also thankful to all residents who cooperated with us in conducting this study and Hoda Khatibi Moghaddam and Najme Shahini who helped us with collecting data.

\section{Disclosure}

The authors report no conflicts of interest in this work.

\section{References}

1. Linzer M. The journal club and medical education: over one hundred years of unrecorded history. Postgrad Med J. 1987;63(740):475-478.

2. Valentini RP, Daniels SR. The journal club. Postgrad Med J. 1997; 73(856):81-85.

3. Accreditation Council for Graduate Medical Education. General competencies. Available from: http://www.ecfmg.org/echo/acgme-corecompetencies.html. Accessed December 21, 2009.

4. Centeno AM, Blanco A, Arce M. Journal club devoted to educational issues. Acad Med. 1999;74(5):464.

5. Lee AG, Boldt HC, Golnik KC, et al. Using the Journal Club to teach and assess competence in practice-based learning and improvement: a literature review and recommendation for implementation. Surv Ophthalmol. 2005;50(6):542-548.

6. Dr Haj ebrahimi, S. Evidence Based Journal Club. Available from: http://ircebm.tbzmed.ac.ir. Accessed July 2014.

7. Shokouhi G, Ghojazadeh M, Sattarnezhad N. Organizing evidence based medicine (EBM) Journal Clubs in Department of Neurosurgery, Tabriz University of Medical Sciences. Int J Health Sci (Qassim). 2012;6(1):59-62.

8. Milbrandt EB, Vincent JL. Evidence-based medicine journal club. Crit Care. 2004;8:401-402.

9. Ramin S, Dabbagh KVR. Effect of evidence based medicine training in the quality of journal clubs: a road to evidence based journal clubs Iranian. J Nucl Med. 2010;18(2):38-44.

10. Allan GM, Korownyk C, Tan A, Hindle H, Kung L, Manca D. Developing an integrated evidence-based medicine curriculum for family medicine residency at the University of Alberta. Acad Med. 2008;83(6):581-587.

11. Heiligman RM, Wollitzer AO. A survey of journal clubs in US family practice residencies. J Med Educ. 1987;62:928-931.

12. Van Derwood JD, Tietze PE, Nagy MC. Journal clubs in family practice programs in the southeast. South Med J. 1991;84:483-487.

13. Alguire PC. A review of journal clubs in postgraduate medical education. J Gen Intern Med. 1998;13:347-353.

14. Akhund S, Masood Kadir M. Do community medicine residency trainees learn through journal club? An experience from a developing country. BMC Med Educ. 2006;6:43.

15. Linzer M, Brown JT, Frazier LM, DeLong ER, Siegel WC. Impact of a medical journal club on house-staff reading habits, knowledge, and critical appraisal skills: a randomized control trail. JAMA. 1988;260:2537-2541.

16. Kellum JA, Rieker JP, Power M, Powner DJ. Teaching critical appraisal during critical care fellowship training: a foundation for evidence-based critical care medicine. Crit Care Med. 2000;28:3067-3070.

17. Cramer JS, Mahoney MC. Introducing evidence based medicine to the journal club, using a structured pre and post-test: a cohort study. $B M C$ Med Educ. 2001;1:6.

18. Macrae HM, Regehr G, McKenzie M, et al. Teaching practicing surgeons critical appraisal skills with an Internet-based journal club: a randomized, controlled trail. Surgery. 2004;136:641-646.

19. Bradley DR, Rana GK, Martin PW, et al. Real-time, evidence based medicine instruction: a randomized controlled trail in a neonatal intensive care unit. J Med Libr Assoc. 2002;90:194-201.

20. Seeling CB. Affecting residents' literature reading attitudes, behaviours, and knowledge through a journal club intervention. J Gen Intern Med. 1991;6:330-334. 
Advances in Medical Education and Practice

Dovepress

\section{Publish your work in this journal}

Advances in Medical Education and Practice is an international, peerreviewed, open access journal that aims to present and publish research on Medical Education covering medical, dental, nursing and allied health care professional education. The journal covers undergraduate education, postgraduate training and continuing medical education including emerging trends and innovative models linking education, research, and health care services. The manuscript management system is completely online and includes a very quick and fair peer-review system. Visit http://www.dovepress.com/testimonials.php to read real quotes from published authors.

Submit your manuscript here: http://www.dovepress.com/advances-in-medical-education-and-practice-journal 